\title{
Contramapeamento indígena: aproximações entre a cartografia crítica e o decolonialismo
}

\author{
Indigenous countermapping: affinities between critical cartography \\ and decolonialism
}

RESUMO

Este estudo trata das relações entre o decolonialismo e a cartografia crítica. Partimos da constatação de que o mapa não é um instrumento neutro de representação do espaço, traduzindo relações de poder. Diante disso, colocamos a seguinte questão: de que maneira a representação do espaço através dos mapas poderia criticar a lógica da colonialidade/modernidade e revelar narrativas reprimidas pelo colonialismo? Apontamos que a resistência ao discurso da colonialidade passa pelas práticas de contramapeamento indígenas.

Palavras-chave: decolonialismo; contramapeamento; mapeamento indígena

\section{ABSTRACT}

This study discusses the relations between decolonialism and critical cartography. We start from the consideration that the map is not a neutral support to represent space, translating power relations. Given this assumption, we ask the following question: how could the representation of space through maps criticize the logic of coloniality/modernity and reveal narratives that are subjugated by colonialism? We propose that the resistance to the discourse of coIoniality could be explored in the indigenous counter-mapping practices.

Keywords: decolonialism; countermapping, indigenous mapping 


\section{INTRODUÇÃO}

Este estudo tem como objetivo aproximar os temas da cartografia crítica (HARLEY, 2001) e do decolonialismo (MIGNOLO, 2007). Argumentamos que as reflexões promovidas pela área conhecida como cartografia crítica podem dialogar com o movimento decolonial, na medida em que assumem a premissa de que o mapa não é um instrumento neutro de representação do espaço. Embora os mapas tenham sido historicamente revestidos de uma aparente objetividade científica, eles não estão isentos de inclinações ideológicas. Pelo contrário, os mapas reforçam relações de poder. Essa característica dos mapas contribuiu de maneira decisiva, por exemplo, para a própria afirmação das nações europeias na conquista colonial do "novo mundo".

O mapa é um artefato semiótico que traduz certos aspectos de uma realidade espacial externa para um determinado intérprete (NÖTH, 1998). Ao fixar características do espaço em um suporte, o mapa se torna um instrumento de apreensão da realidade, estimulando ações de orientação, de deslocamento e de domínio sobre esse espaço. Seja através de relatos de viajantes ou de sofistificadas técnicas de geoprocessamento via satélite, os dados coletados sobre o território são consolidados nesse suporte comunicacional, apoiando decisões estratégicas de exploradores e governantes. Assim, os mapas se revestem de uma espécie de autoridade discursiva sobre o território e se tornam valiosos documentos de teor político.

Uma vez que os mapas não são representações neutras do espaço, sendo historicamente utilizados como instrumentos de imposição de poder sobre o território, lançamos as seguintes perguntas: como poderíamos conceber uma cartografia decolonial? De que maneira a representação do espaço através dos mapas poderia revelar narrativas reprimidas pelo colonialismo? O mapa é um tipo de imagem que pertence a uma cultura visual e que, por sua vez, nos ofereceria "perspectivas de compreensão crítica da realidade" (CUSICANQUI, 2010, p. 20). Portanto, defendemos que o mapa pode ser um registro visual que "nos permite descobrir as formas como o colonialismo é combatido, subvertido e ironizado, agora e sempre" (CUSICANQUI, 2010, p. 6).

Para debater essas questões, propomos uma reflexão sobre o contramapeamento indígena. Trata-se de uma corrente de caráter ativista que procura explorar a linguagem cartográfica a fim de contestar as premissas e as relações de poder presentes em suas convenções. Embora o termo contramapeamento inclua uma diversidade de iniciativas ligadas à reflexão crítica sobre as representações cartográficas de territórios, sua origem é frequentemente associada aos mapeamentos indígenas. Em particular, esses projetos procuram problematizar a representação do espaço indígena, trazendo à tona questões sobre a reivindicação desses territórios e sobre as próprias limitações da cartografia ocidental.

Para isso, este estudo irá trazer um breve panorama do movimento decolonial e da cartografia crítica. Em seguida, trataremos das relações entre a modernidade e a cartografia, a fim de 
reforçar como os mapas são historicamente utilizados como instrumentos de domínio sobre o território. Incentivados pela proposta decolonial de desconstrução do discurso da modernidade, apresentaremos, então, um percurso introdutório pelo contramapeamento indígena. Por fim, apontaremos algumas limitações dessa abordagem, bem como indicaremos lacunas para o aprofundamento futuro nesse debate.

\section{O MOVIMENTO DECOLONIAL}

Uma recente corrente crítica ganha destaque nos círculos acadêmicos das ciências sociais e humanas da América Latina: o chamado decolonialismo (BALLESTRIN, 2013; LUGONES, 2008; MALDONADO-TORRES, 2008; MIGNOLO, 2007; QUIJANO, 2005). Parte-se da constatação de que as relações de colonialidade nas zonas periféricas do mundo não terminaram com o fim do colonialismo. Adotando um tom mais radical em relação aos estudos pós-coloniais, o decolonialismo busca sinalizar mais claramente que, embora os países da América Latina tenham conquistado sua independência política de Portugal e da Espanha, as relações de colonialidade ainda estão presentes. Em outras palavras, a colonialidade ultrapassa o contexto do período colonial, na medida em que permanece como um mecanismo de dominação até os dias de hoje. Haveria, a partir dessa premissa, a urgência de se fomentar epistemologias próprias, cujas categorias de pensamento não mais perpetuem vínculos de dependência (MIGNOLO, 2007).

$\mathrm{O}$ argumento central do movimento decolonial consiste na afirmação de que a colonialidade é a outra face (obscura) da modernidade (MIGNOLO, 2007, p. 31). O projeto moderno dos países europeus está necessariamente vinculado à exploração colonial dos países da América, África e Ásia. De acordo com Quijano (2005, p. 126) a própria consolidação do capitalismo como modo de produção dominante ocorreu graças à exploração colonial da América. Embora as origens do capital antecedam o contexto das grandes navegações, a exploração de recursos por meio do trabalho escravo nas colônias foram determinantes para viabilizar a comercialização de mercadorias e a acumulação do capital pelos países da Europa, financiando o projeto moderno.

A modernidade é um projeto idealizado a partir de um ponto de vista eurocêntrico, através do qual as conquistas intelectuais e culturais da Europa seriam tratadas como indispensáveis para o desenvolvimento das nações. Segundo essa lógica, a relação de exploração colonial dos países periféricos justificaria-se como uma empreitada que levaria o desenvolvimento ao novo mundo, tendo como referência um modelo de sociedade concebido pela Europa. Assim, a colonialidade 
surge como a contrapartida implícita no discurso da modernidade. Por um lado, a modernidade é frequentemente apresentada de maneira positiva, associando-se aos conceitos de progresso, desenvolvimento, prosperidade, democracia e civilização. Por outro lado, a colonialidade é vista como um mal necessário, um legado que "infelizmente" precisa ser considerado para que o ideal moderno seja alcançado. Caberia aos colonizadores europeus o "dever moral" de levar tanto o desenvolvimento quanto o conhecimento aos povos "primitivos". As terras descobertas deveriam ser apropriadas (pois "não tinham dono") e os povos que ali habitavam deveriam ser devidamente instruídos e catequizados. Segundo Quijano (2005), um dos eixos fundamentais de operacionalização desse mecanismo é o conceito de raça, "uma construção mental que expressa a experiência básica de dominação colonial" (QUIJANO, 2005, p. 117). Ou seja, a suposta inferioridade racial dos povos conquistados legitimaria a dominação colonial.

O fato de a modernidade se apresentar como um discurso associado ao progresso esconde, de maneira engenhosa, as articulações geopolíticas por trás da dominação colonial. Trata-se de uma lógica de reprodução de poder que se disfarça em uma falsa neutralidade e objetividade: o homem moderno do "norte" é aquele que, munido do conhecimento científico, seria responsável por levar o saber aos povos ignorantes do "sul". Enquanto o "norte" fornece as teorias e os conceitos, o "sul" se torna um objeto de estudos. Apoiada nesse mecanismo de dominação, a modernidade não somente oculta os efeitos da colonialidade em seu discurso, como também suprime os rastros de qualquer tentativa de enfrentamento ou resistência. Portanto, é preciso refletir sobre a geopolítica da espacialidade na produção de conhecimento e expor que o pensamento ocidental estabeleceu a Europa como locus epistêmico privilegiado (MALDONADOTORRES, 2008).

Sob o ponto de vista decolonial, o "homem moderno do norte" também deve ser entendido em seu sentido literal, e não como mero sinônimo de "ser humano". Além do conceito de raça, a dominação de gênero também é colocada como um relevante problema nesse debate. Nesse sentido, destacamos o trabalho de Lugones (2008). A autora argumenta que as diferenças binárias e hierárquicas de gênero e raça foram introduzidas como ferramentas de dominação pela colonialidade. As categorias isoladas de "mulher" e "negro", por exemplo, seriam insuficientes, pois tornam invisíveis as particularidades que se impõem às mulheres não-brancas. Assim, a luta contra a violência sistemática que acomete as mulheres não-brancas deve considerar a interseccionalidade entre as categorias de raça, classe, sexualidade e gênero. Em outras palavras, a "lógica de separação categorial distorce os seres e fenômenos sociais que existem na interseção" (LUGONES, 2008, p. 82). Portanto, revelar os mecanismos que operam o "sistema moderno-colonial de gênero" (LUGONES, 2008, p. 77) seria fundamental para compreender a profundidade dessa imposição e a inseparabilidade dessas categorias (LUGONES, 2008, p. 82). 
Dessa forma, a reflexão sobre a colonialidade passa, necessariamente, por uma profunda crítica da própria noção de modernidade. Essa crítica deve considerar não somente aspectos econômicos e políticos, mas também sociais e epistemológicos (MIGNOLO, 2007, p. 35). O debate sobre o decolonialismo expõe, por exemplo, os problemas decorrentes e contemporâneos sobre a exploração de mão de obra e de recursos naturais dos países periféricos, as relações de poder e dominação em diferentes instâncias da sociedade, os mecanismos de controle da sexualidade e de gênero, o desenvolvimento da ciência em contraste aos saberes locais e assim por diante.

Em resumo, o chamado giro decolonial seria um movimento de resistência que procura alertar sobre essa lógica que se impõe pela modernidade/colonialidade (BALLESTRIN, 2013). Trata-se de propor narrativas que partem da própria América Latina, oferecendo alternativas ao modelo colonial implantado pelas metrópoles modernas. Consiste em revelar os relatos e pontos de vista dos atores que foram historicamente silenciados pela lógica de poder da colonialidade e, dessa forma, apresentar-se como um contraponto ao projeto moderno.

Neste estudo, propomos discutir o decolonialismo tendo em vista a questão da espacialidade, um problema que, segundo Maldonado-Torres (2008), é central nas reflexões do movimento decolonial. Esse autor indica que a teoria social passa por uma virada espacial comparável à virada linguística ocorrida na filosofia ocidental. Ou seja, o espaço é uma variável que não pode ser ignorada, na medida em que se torna um dos fatores responsáveis por modelar o próprio pensamento filosófico. Assim, para o movimento decolonial, as reflexões sobre a espacialidade evidenciam as intenções por trás do discurso da modernidade. Trata-se de um exercício crítico que valoriza um outro tipo de "lugar de pensamento" que foi, historicamente, ignorado. "A aparente neutralidade das ideias filosóficas pode muito bem esconder uma cartografia imperial implícita que funde espaço e raça" (MALDONADO-TORRES, 2008, parágrafo 71).

Essa linha de argumento indica que conceitos como espaço, lugar, território, fronteiras e representações são fundamentais nas reflexões sobre o decolonialismo. Podemos, então, levantar a seguinte proposta de investigação: explorar o tema do decolonialismo a partir do estudo da cartografia. Ainda que Maldonado-Torres tenha empregado o termo cartografia em seu sentido mais amplo, perguntamos: de que maneira a cartografia - no sentido mais específico, como a ciência da criação dos mapas - seria um recorte válido para os estudos decoloniais? 


\section{O DISPOSITIVO CARTOGRÁFICO}

Uma reflexão crítica sobre as relações de poder que se exercem através da cartografia remete aos estudos da cartografia crítica ${ }^{[1]}$. Trata-se de uma vertente que procurou evidenciar que os mapas sempre estiveram associados ao domínio político do território, particularmente no período de expansão colonial.

A cartografia crítica é uma corrente questiona a aparente neutralidade dos mapas. Seus estudos ganharam projeção a partir da década de 1980, quando um conjunto de pesquisadores com sólida formação em cartografia passa a se interessar pelos aspectos políticos dos mapas e pelas relações de poder que envolvem esse tipo de representação da realidade espacial. Um dos expoentes dessa linha foi o pesquisador J. B. Harley (2001). O principal argumento elaborado pela cartografia crítica consiste em enfatizar que, por trás dos critérios objetivos da ciência cartográfica, encontram-se estratégias discursivas que impõem relações de poder sobre o território (RIBEIRO, 2018).

Os aspectos políticos dos mapas podem, contudo, ocultar-se por trás de seu rigor científico. Amparada por tecnologias sofisticadas de coleta e processamento de dados georreferenciados, a linguagem cartográfica se complexificou consideravelmente no século $\mathrm{XX}$, atribuindo aos mapas um significativo poder de representação do território. De acordo com Harley (2001), os mapas modernos consideram que a realidade poderia ser apreendida a partir de técnicas precisas de observação empírica, mensuração e projeção espacial. Um mapa fiel ao território precisaria se apoiar em métodos científicos capazes de garantir uma correlação válida entre o espaço e o signo cartográfico. Nesse sentido, a verdade cartográfica estaria condicionada à observância criteriosa dessas técnicas por parte do cartógrafo. Dessa maneira, a ciência cartográfica cria mecanismos para classificar e julgar a precisão dos mapas, encarados como instrumentos técnicos.

A cartografia apoia-se na autoridade desse discurso para comunicar relações de poder através dos mapas (HARLEY, 2001). Para desenvolver esse argumento, Harley recupera as reflexões sobre as relações entre conhecimento e poder desenvolvidas por Michel Foucault. Para Foucault, "não há relação de poder sem constituição de um campo de saber, e, reciprocamente, todo saber constitui novas relações de poder" (MACHADO, 2015, p. 28). Essas relações estariam presentes na própria cartografia. Como qualquer outro campo de conhecimento, a cartografia é responsável por estabelecer as regras e os princípios científicos que regem seu objeto de investigação, no caso, os mapas. Mas, ao mesmo tempo, a cartografia é também responsável por perpetuar um mecanismo de exercício de poder através da manutenção desse discurso, acolhido e legitimado como verdadeiro pela sociedade. A esses mecanismos, Foucault deu o nome de dispositivos: um conjunto de estratégias de manipulação de relações de poder que condicionam certos tipos de saber (AGAMBEN, 2014). 
Considerando essa definição, podemos afirmar que o mapa é um dispositivo, e que Harley estava justamente interessado em evidenciar a presença do poder - e seus efeitos - nos mapas (RIBEIRO, 2018, p. 38). Harley cita diversas situações em que o discurso de poder dos mapas se evidencia. Por exemplo: há certas convenções cartográficas que, por hábito, tornam-se inquestionáveis, como o fato de os mapas tradicionalmente representarem o norte na parte de cima ou posicionarem o continente europeu no centro de um planisfério retangular. Outra crítica apontada por Harley refere-se às distorções provocadas pela técnica de projeção de Mercator nos mapas-múndi. Essa técnica faz com que os continentes que se encontram em latitudes mais altas pareçam maiores, 0 que teria contribuído para reforçar um discurso de superioridade dos países do norte, sobretudo da Europa. Por fim, Harley também menciona inúmeros casos em que a cartografia foi utilizada como instrumento ideológico imperialista, a fim de legitimar conquistas coloniais:

Tanto quanto armas de fogo e navios de guerra, mapas são armas do imperialismo.
Desde que os mapas foram usados na promoção colonial e terras foram
reivindicadas no papel antes mesmo de serem efetivamente ocupadas, mapas
anteciparam impérios (...) Eles ajudaram a criar mitos que poderiam ajudar na
manutenção do status quo territorial (HARLEY, 2001, p. 57-58, tradução nossa).

Em resumo, as reflexões promovidas pela cartografia crítica evidenciaram que os mapas não estão isentos de inclinações ideológicas. O mapa é um artefato comunicacional situado em um contexto social e histórico, que refrata uma determinada perspectiva da realidade. Mesmo amparada por técnicas rigorosas de mapeamento, a ciência cartográfica não seria capaz de neutralizar essa característica retórica dos mapas. Todo mapa é um signo parcial e, portanto, ideológico (BAKHTIN, 2004), e não uma janela transparente para o mundo.

\section{A CARTOGRAFIA E A INVENÇÃO DA AMÉRICA}

Não é por acaso que o aprimoramento das técnicas da cartografia esteja vinculado ao próprio desenvolvimento do discurso da modernidade. A partir do contexto das grandes navegações, as técnicas cartográficas se tornaram cada vez mais sofisticadas, permitindo que exploradores europeus pudessem alcançar, com mais segurança, regiões que se encontravam muito além de suas fronteiras conhecidas, dando início à dominação colonial da América (BROTTON, 2014).

Antes do desembarque dos europeus deste lado do Atlântico, o "mundo conhecido" era dividido em três continentes (Europa, Ásia e África). Essa divisão do mundo aparece nos famosos mapas circulares T-O do período medieval (figura 1). Trata-se de uma representação espacial 
fortemente influenciada por aspectos religiosos, que remetem tanto à tríade cristã como também a trechos do antigo testamento (ECO, 2013). Essa divisão, que coloca Jerusalém no centro do mapa, dificultou a incorporação de um quarto continente (a América) no imaginário dos europeus daquela época (ZUMTHOR, 1993).

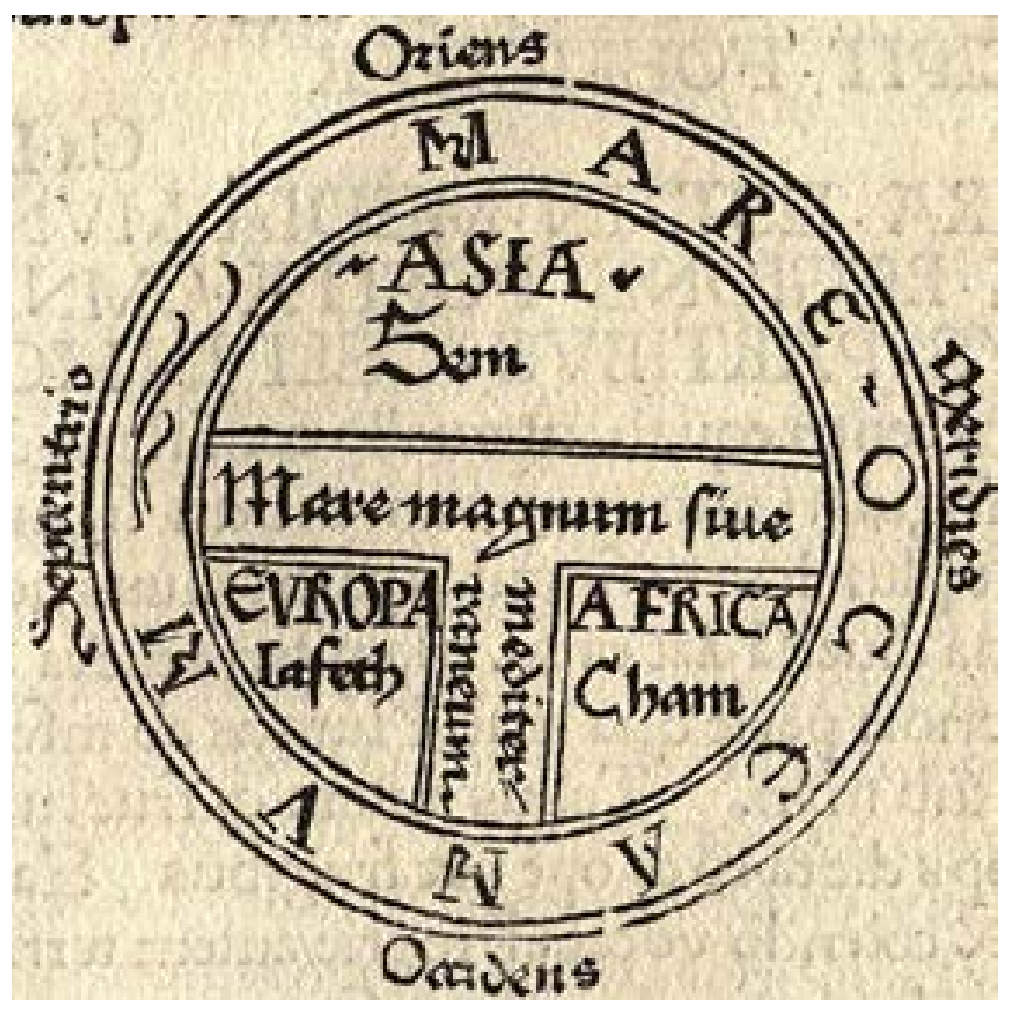

FIGURA 1: Mapa T-O.

Fonte: Wikimedia Commons .

A América passa a "existir" somente quando os navegantes europeus desembarcam em nossas praias e os traçados do nosso continente começam a aparecer nos mapas a partir do século XVI. Dessa maneira, o continente foi progressivamente apropriado e integrado ao imaginário europeu. Ou seja, a "invenção" da América permitiu a expansão imperial e criou as condições para que fosse idealizado um projeto europeu que se tornou uma referência de progresso para a humanidade (MIGNOLO, 2007, p. 31-32). A característica eurocêntrica dessa perspectiva se evidencia, por exemplo, na maneira como a maioria dos mapas-múndi são projetados, tendo o continente europeu acima e no centro. A própria disputa territorial entre Portugal e Espanha no século XVI revela como os mapas foram tratados como instrumentos de legitimação de poder sobre o território. 
políticos aceitavam como juridicamente válido devido ao seu papel fundamental em um tratado internacionalmente acordado e confirmado pelo Papa. Mapas como aquele poderiam resolver disputas em torno de lugares no globo terrestre que os cartógrafos e seus patrões políticos jamais haviam visto, muito menos visitado. Eles também se arrogavam um novo grau de objetividade científica baseado em relatórios e registros verificáveis de viagens de longa distância, em vez de boatos e suposições clássicas (BROTTON, 2014, p. 223).

As pesquisas sobre a cartografia crítica mostram como o traçado dos mapas, das fronteiras e das projeções embutem relações de poder que foram historicamente responsáveis por construir discursos coloniais (HARLEY, 2001; BROTTON, 2014). O próprio desenvolvimento da ciência cartográfica esteve alinhado com o projeto moderno de expansão econômica e territorial europeia (HARVEY, 2012). Ou seja, o aprimoramento de instrumentos e técnicas de navegação durante o período das expansões marítimas foi fundamental para a consolidação da cartografia. Dessa maneira, podemos dizer que os mapas refletem - em sua própria lógica de construção - modelos de pensamento colonial, em grande parte responsáveis por traçar o novo mundo conforme os interesses das metrópoles colonizadoras.

De fato, o próprio tema da cartografia foi explorado pelos autores do movimento decolonial. Mignolo (2007, p. 17), por exemplo, lembra que a maneira como os mapas da América do período colonial foram traçados refletem o ponto de vista europeu, colocando o novo continente - ou terra incognita (BROTTON, 2014) - como um objeto de exploração na nova ordem mundial. A invenção da América (e sua consequente aparição nos mapas) é um elemento chave para a criação da ideia de modernidade, pois financiou o projeto desenvolvimentista das metrópoles européias através da exploração das colônias. A América seria encarada, sob essa perspectiva, como uma vasta extensão de terra onde os recursos naturais são abundantes e que se encontra à espera de desenvolvimento.

Há, portanto, uma evidente associação entre o discurso da modernidade e o desenvolvimento da cartografia. De maneira análoga, levantamos a hipótese de que haveria também afinidades entre os debates sobre o decolonialismo e cartografia crítica, na medida em que ambas correntes buscam rupturas nos discursos hegemônicos em seus respectivos domínios de estudo, valorizando visões alternativas de mundo. Acreditamos que essas afinidades poderiam ser exploradas, por exemplo, nas propostas alternativas de mapeamento, particularmente nos mapeamentos indígenas. 


\section{O PENSAMENTO FRONTEIRIÇO DE FELIPE POMA}

Ao reforçar que todo mapa propõe uma certa visão da realidade, a cartografia crítica abriu as portas para que outras propostas de mapeamento pudessem ser valorizadas. Assim, a partir dos questionamentos levantados pela cartografia crítica, passou-se a admitir que a cartografia científica não detém a verdade exclusiva sobre as representações do território. Diferentes visões de mundo igualmente válidas poderiam ser exploradas em outros domínios por onde a cartografia transita, seja nas artes, nos mapeamentos indígenas ou nas práticas ativistas de contramapeamento (WOOD, 2010; RIBEIRO, 2018). Interessa-nos, aqui, destacar mapeamentos alternativos que sejam capazes de evidenciar distintas relações espaciais no contexto do debates sobre o decolonialismo.

Sugerimos que uma possível frente de fomento à cartografia decolonial estaria em sintonia com o pensamento fronteiriço, descrito por Mignolo (2007). Segundo esse autor, o pensamento fronteiriço enaltece a resistência à lógica colonial que sobrevive às margens da sociedade. Encontra-se, por exemplo, nos ritos e nas manifestações populares de grupos marginalizados da América Latina e da Europa periférica. Por mais que haja tentativas recorrentes de supressão de sua materialidade e seus registros, esse pensamento fronteiriço ainda sobrevive nesses corpos marginais. Trata-se de um convite para se explorar as histórias que surgem nas fronteiras, e não nas narrativas oficiais dos expansionismos europeus e estadunidenses.

Segundo Mignolo (2007, p. 170), "um claro exemplo de pensamento fronteiriço" pode ser encontrado no mapa conhecido como Pontifical Mundo (figura 2), criado por Felipe Guaman Poma, um cronista indígena nascido aproximadamente em 1545 na região de Huamanga, atualmente Huamachuco, no Peru. Poma criou, por volta de 1612, uma obra chamada Nueva Corónica y Buen Gobierno, constituída de escritos e desenhos relacionados ao mundo indígena ao qual ele pertencia. Segundo os pesquisadores Vargas, Aguerre e Cabello (2001), Poma não só descreve as principais autoridades espanholas e indígenas daquela região, como também denuncia abusos e maus tratos sobre os indígenas para o rei da Espanha. Ainda que tenha recebido uma educação religiosa, Poma preservou, em seus desenhos, categorias indígenas que tratam do "ser no mundo" e que explicam, por exemplo, as origens do mundo indígena e do mundo ocidental. Segundo Cusicanqui (2010, p. 23), a obra de Poma apresenta "argumentos contundentes contra a usurpação de terras e a exploração laboral", apoiando-se numa espécie de "teorização visual do sistema colonial" identificada pela autora como "Mundo ao Revés" (CUSICANQUI, 2010, p. 22). Assim, a maneira como a sociedade indígena se organiza temporalmente e espacialmente é entendida por Poma como uma "ordem justa" e um "bom governo" (CUSICANQUI, 2010, p. 25), em contraste com o modelo dos colonizadores. 


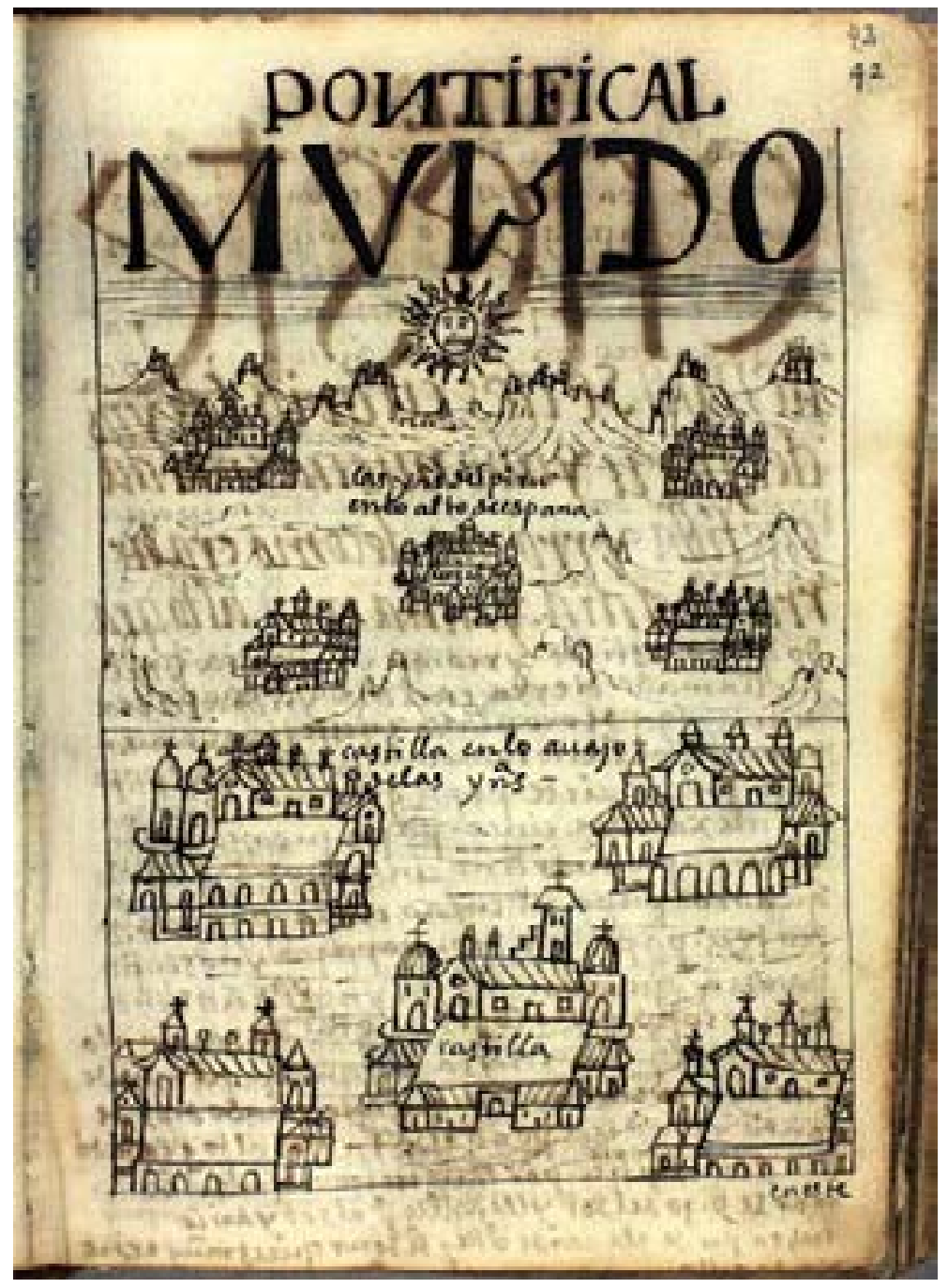

FIGURA 2: Mapa Pontifical Mundo.

Fonte: Det Kongelige Bibliotek .

A compreensão de seus desenhos deve levar em conta o modelo de pensamento indígena, que concebia o mundo através de uma rigorosa hierarquia baseada em oposições do tipo "acimaabaixo", "esquerda-direita", "masculino-feminino", "jovem-idoso", "céu-terra" etc. Assim, foi possível identificar uma lógica de organização espacial em seus desenhos, que contemplava o mundo em quatro direções: Chinchaysuyu (Curso Norte), Antisuyu (Curso Leste), Collasuyu (Curso Sul) e Cuntisuyu (Curso Oeste), que culminava com a cidade de Cuzco no centro ou no "umbigo do mundo" (VARGAS; AGUERRE; CABELLO, 2001).

No mapa Pontifical Mundo, Poma propõe uma síntese do mundo conhecido, dividindo-o em duas partes: na metade superior encontra-se o mundo indígena e, na metade inferior, encontrase o mundo ocidental, representado pelo império espanhol. A parte de cima é definida como 
"As Índias do Peru no alto da Espanha", e contém cinco conjuntos que marcam os quatro cursos do mundo andino, tendo a cidade de Cuzco em seu centro. A parte de baixo repete o mesmo esquema, porém com o reino de Castilla no centro. Há uma clara intenção do autor em destacar uma hierarquia que coloca as estruturas do mundo andino sobre as estruturas do mundo ocidental (VARGAS; AGUERRE; CABELLO, 2001).

Segundo Mignolo (2007), o mapa de Guaman Poma se contrapõe tanto aos mapas T-O do período medieval quanto ao mapa Orbis Universalis Terrarum, de Ortelius ${ }^{[2]}$. Nesses mapas, há uma "cumplicidade entre a geografia e a epistemologia", mas que, no mapa de Poma, se mostra de uma maneira totalmente diferente, revelando uma "condição inevitável dos sujeitos subalternos coloniais" (MIGNOLO, 2007, p. 170). O mapa de Poma seria uma demonstração do pensamento fronteiriço por apresentar um "potencial para a construção de projetos políticos e epistemológicos decoloniais" (MIGNOLO, 2007, p. 170).

Nessa análise, Mignolo revela que o ponto de vista indígena foi fundamental para se pensar o território através de uma representação alternativa. Tomando como referência categorias de pensamento que derivam de sua própria experiência, Poma indicou que é possível conceber o mundo de outra maneira. Cusicanqui (2010, p. 26) acrescenta que os desenhos de Poma "contêm elementos conceituais e teóricos que se transformam em poderos argumentos críticos", apontando para a o caráter ilegítimo do governo colonial. Nesse sentido, o mapa de Poma pode ser considerado um exemplo embrionário de contramapeamento, um exercício crítico de criação de mapas que desafia o dispositivo cartográfico, propondo alternativas de representação do espaço.

\section{CONTRAMAPEAMENTO INDÍGENA}

Os estudos sobre o mapeamento indígena são relativamente recentes, tendo início na década de 1970. As principais publicações se concentram no Canadá e nos EUA, o que indica uma carência de referências sobre esse tema na América Latina. Um panorama de estudos e publicações sobre o mapeamento indígena pode ser encontrado em Chapin et al (2005). Tais autores apontam que essas práticas abrangem tanto o mapeamento feito para os indígenas quanto o mapeamento feito pelos indígenas. Ambas as abordagens possuem um caráter político, cujo propósito contempla o suporte à defesa de recursos naturais e territórios ancestrais desses povos (WAINWRIGHT; BRYAN, 2009). 
Encontramos em McGurk e Caquard (2020) uma pesquisa mais extensa sobre projetos online de mapeamento indígena no Canadá. Nesse estudo, os pesquisadores investigam como aplicações de mapeamento utilizando ferramentas digitais poderiam representar comunidades indígenas. A pesquisa promoveu uma revisão sistemática de mapeamentos, complementada por entrevistas com criadores e usuários desses projetos, incluindo pesquisadores e ativistas de origem indígena.

Há distintas técnicas e metodologias de mapeamento indígena, tais como mapeamentos ligados às atividades de subsistência (pesca, caça, coleta), mapeamento participativo, etnocartografia e contramapeamentos. Recentemente, a popularização de tecnologias de GPS (global positioning system) deu origem a métodos de mapeamento indígena que combinam coleta de dados via satélite e processamento digital usando plataformas de GIS (geographic information system). Contudo, ainda que o uso da tecnologia facilite o diálogo com autoridades ou representantes governamentais, tais abordagens também estão sujeitas a críticas, uma vez que estão amplamente dependentes de procedimentos científicos "ocidentais", limitando o papel dos próprios povos indígenas (CHAPIN et al., 2005, p. 629). Assim, o ponto de vista indígena é frequentemente representado de maneira incompleta (CHAPIN et al., 2005, p. 620).

A vertente ativista dos mapeamentos indígenas derivou uma corrente conhecida como contramapeamento (conter-mapping). Harris e Hazen (2005) definem contramapeamento como as atividades que contestam as premissas e as relações de poder presentes nas convenções cartográficas, desafiando seus efeitos e propondo novas alternativas de mapeamento. Segundo Peluso (1995), o movimento de contramapeamento surgiu como uma iniciativa de ativistas que, por meio de rascunhos e desenhos, buscaram delinear a reivindicação de populações locais na Indonésia sobre a delimitação de suas reservas e recursos naturais. O contramapeamento se apresenta como uma estratégia de resistência que propõe alternativas à imposição arbitrária de fronteiras, "expressando relações sociais no espaço em vez de representar o espaço abstrato em si mesmo" (PELUSO, 1995, p. 387).

Assim, o termo contramapeamento é frequentemente associado aos estudos e às práticas de mapeamento indígena. Esse movimento gerou, nos últimos anos, diversas iniciativas, agregando cartógrafos, artistas, indígenas e antropólogos. Reflexões sobre as possibilidades e os limites dos contamapeamento indígenas foram organizadas por Sletto (2009) em uma edição especial do periódico Cultural Geographies. Nessa publicação, pesquisadores debatem projetos de contramapeamentos de territórios indígenas na América Latina, no Canadá, Tailândia e Tibete. Podemos também citar o projeto Mapping Back! Indigenous Cartographies of Extractive Conflicts $^{[3]}$, desenvolvido por pesquisadores ligados ao Geomedia Lab da Concordia University em Montreal, Canadá. Um dos objetivos do projeto é reunir pesquisadores da cartografia 
interessados em desenvolver "novas formas de expressão espacial, dedicadas a incorporar e expressar perspectivas indígenas sobre os lugares" (CAQUARD; STUDNICKI-GIZBERT; TEMPER, 2017). Esse projeto gerou um atlas colaborativo, que abriga uma coletânea de mapas e promove práticas de mapeamento indígena.

Outro exemplo é o projeto de contramapeamento Zuni Map Art Project (LOFTEN; VAUGHANLEE, 2018), uma iniciativa conduzida pelo A:shiwi A:wan Museum and Heritage Center, entre os anos de 2006 e 2013. O projeto reuniu cerca de vinte pinturas de artistas Zuni, um grupo indígena da região Halona:wa, local que hoje se situa entre os estados do Novo México e do Arizona, nos Estados Unidos. Recuperando narrativas de seus ancestrais, o projeto promoveu a recriação de mapas que pudessem reivindicar os nomes tradicionais utilizados pelos Zuni em seus territórios, retratando a paisagem à sua maneira (figuras 3 e 4). A perspectiva espacial dos Zuni leva em conta o entralaçamento de cultura, história e religiosidade. Os mapas criados a partir do ponto de vista do povo Zuni desafiam noções da cartografia ocidental e questionam a arbitrariedade das fronterias que foram impostas na demarcação desses territórios pelas autoridades governamentais (LOFTEN; VAUGHAN-LEE, 2018), principalmente no período das políticas de expansão territorial dos EUA para o oeste. Além dos mapas, um documentário em vídeo foi produzido, tendo como protagonista Jim Enote, indígena Zuni e diretor do museu A:shiwi A:wan (figuras 5 e 6 ).

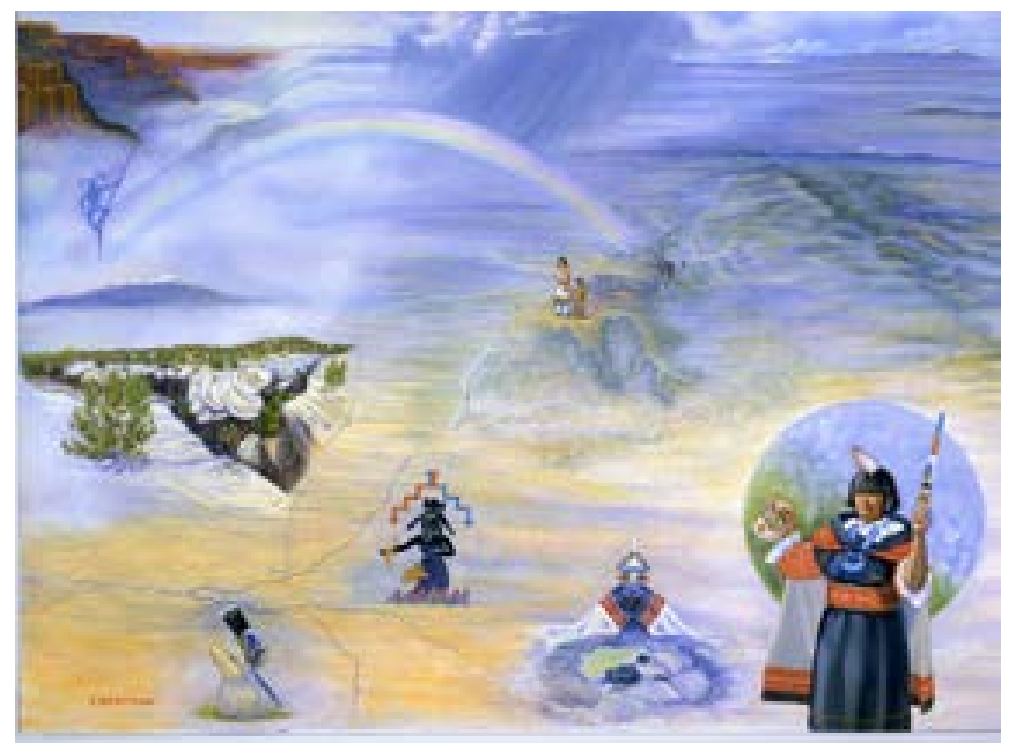

FIGURA 3: K'yawakwayina:we (Waterways), de Edward Wemytewa, 2006.

Fonte: Loften e Vaughan-Lee (2018). 


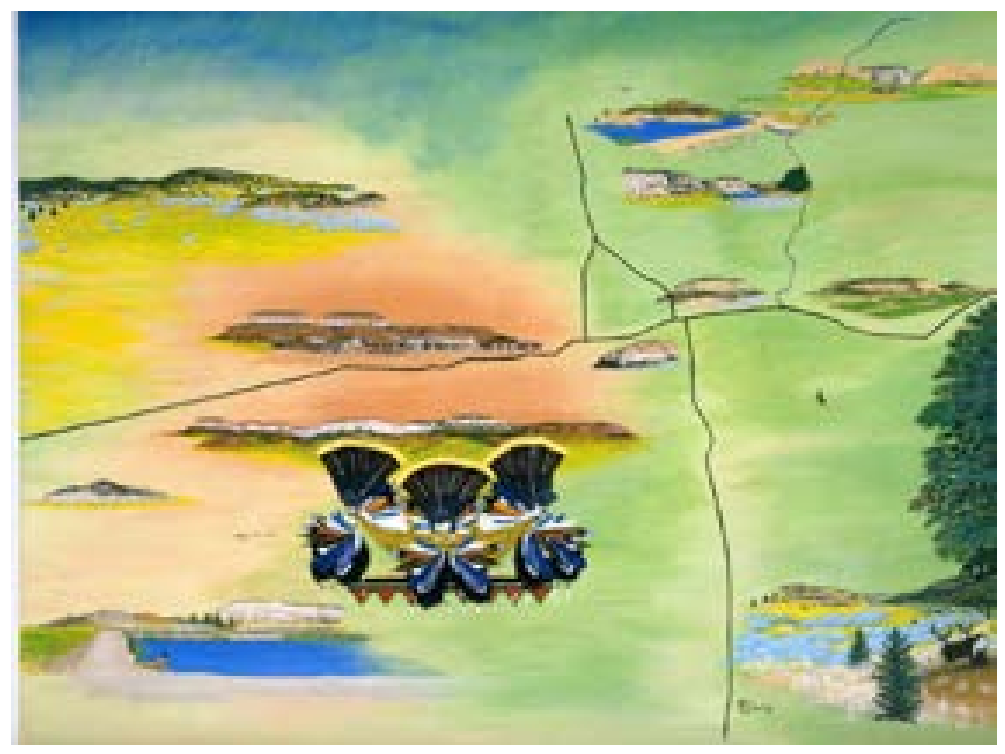

FIGURA 4: Ho'n A:wan Dehwa:we (Our Land), de Ronnie Cachini, 2006. Fonte: Loften e Vaughan-Lee (2018).

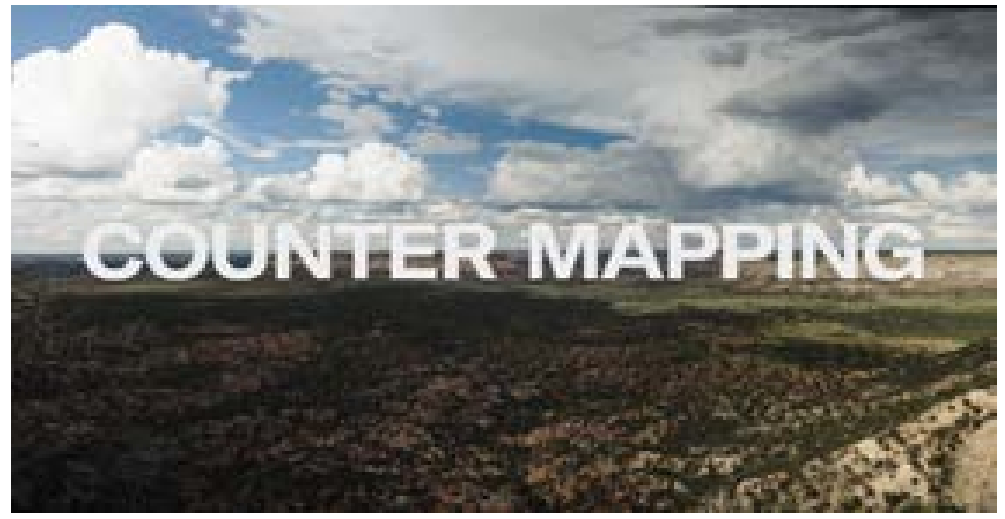

FIGURA 5: Frame do vídeo documentário Counter Mapping, de Loften e Vaughan-Lee (2018). 


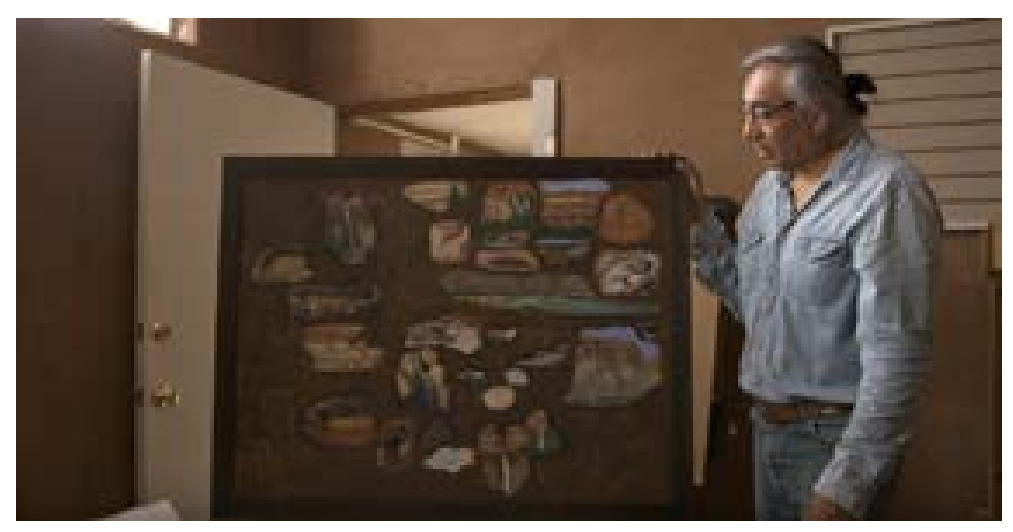

FIGURA 6: Frame do vídeo documentário Counter Mapping, onde Jim Enote exibe um dos quadros pintados pelos artistas Zuni. Fonte: Loften e Vaughan-Lee (2018).

\section{CRÍTICAS E APONTAMENTOS FUTUROS}

Como vimos, a cartografia foi bastante utilizada por governantes para reivindicar a posse de recursos e terras, um exercício de poder que frequentemente vitimizou povos indígenas. Nesse sentido, o mapeamento indígena representa uma mudança significativa na maneira como a cartografia pode ser encarada e praticada. Os contramapeamentos indígenas apontam para subversões da ciência cartográfica, uma disciplina que (literalmente) traçou uma visão colonial sobre os continentes. Dessa maneira, os contramapeamentos são iniciativas que almejam perturbar as próprias categorias que constituem as relações de poder da modernidade (SLETTO, 2009, p. 148; WAINWRIGHT; BRYAN, 2009, p. 170).

Portanto, o atual interesse pelas iniciativas de contramapeamento indígena dialoga com as reflexões levantadas pelo decolonialismo. A natureza crítica desses projetos provoca questões sobre as relações de poder que envolvem a representação do território através dos mapas. Por exemplo: como os projetos de mapeamento empoderam ou marginalizam povos indígenas? Seria possível empregar técnicas de mapeamento para preservar conhecimentos locais? Ou, ao contrário, estaríamos impondo padrões ocidentais de pensamento que descaracterizam os saberes locais? (CHAPIN et al., 2005).

Nessa linha, Sletto (2009) reforça que, embora os mapeamentos indígenas sejam relevantes para a reivindicação de direitos desses povos sobre o território, essas práticas podem gerar resultados limitados. Segundo esse autor, a criação de mapas geralmente envolve um processo 
de abstração que requer a fixação do espaço baseada em parâmetros rígidos e precisos. Tais exigências contradizem a própria noção fluida, móvel e contingente dos indígenas sobre a natureza e o espaço. Ao abstrair a complexidade como os indígenas encaram os espaços vividos, os mapas gerados certamente perderiam parte de seu potencial crítico.

Afinal, como lembram McGurk e Caquard (2020), a maneira como os mapas são tratados pelos próprios povos indígenas costuma diferir, radicalmente, da noção ocidental de mapeamento. Suas práticas adotam linguagens e formas que variam desde gravuras em madeiras, costuras em tecidos ou mesmo o compartilhamento de noções espaciais por meio de narrativas orais. Esses autores também apontam que as práticas tradicionais de mapeamento indígena costumam priorizar o próprio processo de mapeamento, composto por gestos, memórias, performances e narrativas, ao invés do produto final (o mapa). "Quando os mapas são vistos como processos, abrem-se portas para formas mais experimentais de mapeamento que podem melhor mobilizar as forças de formatos orais e performáticos como formas de transmissão do conhecimento indígena" (MCGURK, CAQUARD, 2020, p. 52).

Por isso, um problema relevante nas tentativas de representação do espaço sob o ponto de vista indígena é a questão das fronteiras. A fronteira é um dos signos principais em um mapa e sua delimitação muitas vezes resulta de decisões arbitrárias (ANZALDÚA, 2012; POPESCU, 2012). Sletto (2009) alerta que uma fronteira pode partir de premissas baseadas em falsos dualismos - "entre natureza e cultura, entre indígena e não-indígena, entre ciência e conhecimento local" (SLETTO, 2009, p. 148). Assim, segundo esse autor, a representação de uma fronteira acaba estipulando divisões impermeáveis em um território. Do ponto de vista indígena, ao contrário, uma fronteira se define frequentemente pelo movimento e por redes flutuantes de relacionamento, tais como conexões familiares, padrões de migração e disponibilidade de recursos (SLETTO, 2009 , p. 150). Ou seja, a nossa noção de fronteira é um conceito rígido que se contrapõe às categorias de espaço normalmente adotadas pelos indígenas.

Uma alternativa para se romper com a rigidez das representações cartográficas tradicionais e problematizar formas tradicionais de conceber o mapeamento passa pelo domínio das artes. As interseções entre arte e cartografia há muito apontam para representações alternativas do espaço (COSGROVE, 2005; HARMON, 2009; WOOD, 2010). De acordo com Prenser (2019, p. 14), a arte nos ajuda a integrar as dimensões emotiva, qualitativa e experiencial na maneira como pensamos sobre os mapas e o mapeamento. Livre do compromisso de se enquadrar nas convenções da cartografia científica, a arte cartográfica provoca distúrbios na concepção tradicional dos mapas. Ou seja, "as possibilidades mais intrigantes sobre os mapas são aquelas que se abrem para vozes alternativas, práticas de contramapeamento, de libertação e de revide" (PRESNER, 2019, p. 23). Assim, ao experimentar diferentes materiais, formas e suportes, as 
interseções entre arte e cartografia seriam capazes de evidenciar aspectos mais qualitativos do território, tais como experiências subjetivas, memórias e temporalidades (PRESNER, 2019, p. 14). Trata-se de propriedades fundamentais em uma concepção indígena de mundo.

Por fim, a proposta de se estudar o movimento decolonial sob o recorte da cartografia crítica não está livre de críticas. Por se tratar de um movimento que foi essencialmente conduzido por pesquisadores do "norte", a cartografia crítica poderia ser questionada quanto à suas raízes epistemológicas. Ainda sim, acreditamos que as ideias da cartografia crítica aplicadas aos contramapeamentos indígenas proporcionam, no mínimo, uma relevante reflexão sobre o problema da espacialidade no decolonialismo.

\section{REFERÊNCIAS}

AGAMBEN, Giorgio. O amigo \& O que é um dispositivo? Chapecó, SC: Argos, 2014.

ANZALDÚA, Gloria. Borderlands/La Frontera: The new mestiza. San Francisco: Aunt Lute Books, 2012.

BAKHTIN, Mikhail. Marxismo e filosofia da linguagem: problemas fundamentais do método sociológico na ciência da linguagem. 11. ed. São Paulo: HUCITEC, 2004.

BALLESTRIN, Luciana. América Latina e o giro decolonial. Revista brasileira de ciência política, n. 11, 2013, p. 89-117. BROTTON, Jerry. Uma história do mundo em doze mapas. Rio de Janeiro: Zahar, 2014.

CAQUARD, S; STUDNICKI-GIZBERT, D.; TEMPER, L. Mapping Back! Indigenous Cartographies of Extractive Conflicts. Website do workshop realizado pelo Geomedia Lab na Concordia University, Montreal/CA. Outubro de 2017. Disponível em: <http://www.geomedialab.org/mapping_back.html>. Acesso em: 17 mar. 2019.

CHAPIN, Mac; ZACHARY, Lamb; THRELKELD, Bill. Mapping indigenous lands. Annual Review of Anthropology, v. 34, p. 619-638, 2005. Disponível em: <https://www.jstor.org/stable/25064901>. Acesso em 03 set. 2019.

COSGROVE, Denis. Maps, mapping, modernity: Art and cartography in the twentieth century, Imago Mundi, v. 57(1), 2005, p. 35-54. Disponível em: <http://dx.doi.org/10.1080/0308569042000289824>. Acesso em: 2 set. 2017. CUSICANQUI, Sivlvia Rivera. Chixinakax utxiwa: una reflexión sobre prácticas y discursos descolonizadores - 1a ed. - Buenos Aires: Tinta Limón, 2010.

ECO, Umberto. História das terras e lugares lendários. Rio de Janeiro: Record, 2013. 
HARLEY, J. B. The new nature of maps: essays in the History of Cartography. Baltimore: The Johns Hopkins University Press, 2001.

HARMON, Katharine. The Map as Art: contemporary artists explore cartography. New York: Princeton Architectural Press, 2009.

HARRIS, Leila M.; HAZEN, Helen D. Power of maps: (Counter) mapping for conservation. ACME: International E-Journal for Critical Geographies, v. 4, n. 1, 2005, p. 99-130.

HARVEY, David. Condição pós-moderna: uma pesquisa sobre as origens da mudança cultural. 23. ed. São Paulo: Edições Loyola, 2012.

LOFTEN, Adam; VAUGHAN-LEE, Emmanuel. Counter Mapping. Emergence Magazine. California, EUA: Kalliopeia Foundation, 2018. Disponível em: < https://emergencemagazine.org/story/counter-mapping/>. Acesso em: 30 set. 2020.

LUGONES, María. Colonialidad y Género. Tabula Rasa, Bogotá , n. 9, p. 73-102, Dez. 2008. Disponível em: $<$ http://www.scielo.org.co/scielo.php?script=sci_arttext\&pid=S1794-24892008000200006\&lng=en\&nrm=iso>. Acesso em 26 set. 2020.

MACHADO, Roberto. Introdução: por uma genealogia do poder. In: FOUCAULT, Michel. Microfísica do Poder. 3. ed. Rio de Janeiro: Paz e Terra, 2015.

MALDONADO-TORRES, Nelson. A topologia do ser e a geopolítica do conhecimento. Modernidade, império e colonialidade. Revista crítica de ciências sociais, v. 80, 2008. p. 71-114. Disponível em: < http://journals.openedition. org/rccs/695 >. Acesso em: 09 set. 2019. DOI : 10.4000/rccs.695

MIGNOLO, Walter. La idea de America Latina: a herida colonial la opción decolonial. Barcelona: Gedisa Editorial, 2007.

MCGURK, Thomas. CAQUARD, Sébastien. To what extent can online mapping be decolonial? A journey throughout Indigenous cartography in Canada. The Canadian Geographer / Le Géographe canadien. Canadian Association of Geographers / L’Association canadienne des géographes, v. 64, n. 1, 2020, p. 49-64. DOI: 10.1111/cag.12602

NÖTH, Winfried. Cartossemiótica. In: OLIVEIRA, Ana Claudia; FECHINE, Yvana. Visualidade, urbanidade, textualidade. São Paulo: Hacker, 1998.

PELUSO, Nancy L. Whose Woods Are These? Counter- Mapping Forest Territories in Kalimantan, Indonesia. Antipode, v. 27, n. 4. 1995. p. 383-406. http://dx.doi.org/10.1111/j.1467-8330.1995.tb00286.x

POPESCU, Gabriel. Bordering and ordering the twenty-first century: understanding borders. Plymouth, UK: Rowman \& Littlefield, 2012. 
PRESNER, Todd. Entrevista concedida a Daniel Melo Ribeiro. In: TECCOGS: Revista

Digital de Tecnologias Cognitivas, n. 19, jan./jun. 2019, p. 11-28. Disponível em: < http://www4.pucsp.br/pos/ tidd/teccogs/entrevistas/2019/edicao 19/teccogs19 entrevista01.pdf $>$. Acesso em: 7 set. 2019.

QUIJANO, Aníbal. Colonialidade do poder, Eurocentrismo e América Latina. In: LANDER, Edgardo (org.). A colonialidade do saber: eurocentrismo e ciências sociais, perspectivas latino-americanas. Buenos Aires: Consejo Latinoamericano de Ciencias Sociales, 2005. p. 117-142. Disponível em: < http://biblioteca.clacso.edu.ar/clacso/ sur-sur/20100624103322/12_Quijano.pdf>. Acesso em: 27 set. 2020.

RIBEIRO, Daniel Melo. Limiares da cartografia: deambulação, arqueologia e montagem no mapeamento de lugares. 2018. 298 p. Tese (Doutorado em Comunicação e Semiótica) - Pontifícia Universidade Católica de São Paulo, São Paulo, 2018.

SLETTO, Bjørn. Special issue: Indigenous cartographies. Cultural geographies, v. 16, p. 147-152, 2009. DOI: $10.1177 / 1474474008101514$

VARGAS, C. G.; AGUERRE, H. R.; CABELLO, F. S. Sinopsis del estudio de la iconografía de la nueva coronica y buen gobierno escrita por Felipe Guaman Poma de Ayala. Historia (Santiago), Santiago, v. 34, 2001, p. 67-89. Disponível em: <https://scielo.conicyt.cl/scielo.php?script=sci_arttext\&pid=S0717-71942001003400003\&lng=es $\& n r m=$ iso $>$. Acesso em: 10 mar. 2019. DOI: 10.4067/S0717-71942001003400003

WAINWRIGHT, Joel; BRYAN, Joe. Cartography, territory, property: postcolonial reflections on indigenous counter-mapping in Nicaragua and Belize. Cultural geographies, v. 16, p. 153-178, 2009. DOI: 10.1177/1474474008101515.

WOOD, Denis. Rethinking the power of maps. New York: The Guilford Press, 2010.

ZUMTHOR, Paul. La mesure du monde: representation de l'espace au moyen âge. Paris: éditions du seuil, 1993.

[1] De maneira mais aprofundada, o tema da cartografia crítica e suas relações com o campo da comunicação foram anteriormente desenvolvidos por este autor em Ribeiro (2018).

[2] Disponível em: <https://en.wikipedia.org/wiki/Abraham_Ortelius>. Acesso em: 09 set. 2019.

[3] Disponível em: <http://mappingback.org/>. Acesso em: 09 set. 2019. 